\title{
STUDI PEMANFAATAN JENIS BAMBU OLEH MASYARAKAT DAYAK BAKATI DI HUTAN ADAT DESA TANJUNG KECAMATAN TERIAK KABUPATEN BENGKAYANG
}

\author{
(Study of the Utilization of Bamboo Type by a People's Community Forest in the Forest of \\ Tanjung Village, Teriak Sub-District, Bengkayang District)
}

\author{
Junisa, H.A. Oramahi, Gusti Eva Tavita \\ Fakultas Kehutanan Universitas Tanjungpura Pontianak. Jl. Daya Nasional Pontianak 78124 \\ Email: ajunjunisa@gmail.com
}

\begin{abstract}
The purpose of this study was to obtain data on the types of bamboo used by the community and study the patterns of bamboo utilization by the people of Tanjung Village, Teriak District, Bengkayang Regency. The research was conducted in Tanjung Peninsula Village Teriak District Bengkayang Regency \pm 4 weeks effective in the field. The tools used include location maps, GPS, herbarium equipment (alcohol, plastic packing, newspapers, scissors, insulation and hanging labels), cameras, questionnaires, tally sheets, recording devices, gloves, machetes, knives and cuttings. The method used is a survey and observation method with direct interview techniques. Sampling is done by using purposive sampling. Based on data obtained at the study site, 10 types of bamboo were utilized by the people of Tanjung Village, Teriak District, Bengkayang Regency, which were found are (Bambusa multiplex), (Bambusa vulgaris), (Dendracalamus asper), (Dendrocalamus hirtellus), (Gigantochloa ater), (Gigantochloa balui), (Gigantochloa hasskarliana), (Gigantochloa levis), (Schantz brachycladum), (Schzostachyum flexuosum). All types of bamboo are used in the from of craft (13 kinds of utilizion), consumption (3 kinds of utilizion), ritual costoms ( 7 kinds of utilizion), medicine (2 kinds of utilizion) and farming implements (15 kinds of utilizion).
\end{abstract}

Keyword: Bamboo, Tanjung village, Utilization, Community forest

\section{PENDAHULUAN}

Hutan merupakan suatu kawasan yang ditumbuhi dan didominasi oleh pepohonan dengan kerapatan, serta menutupi areal yang luas. Tumbuhtumbuhan tidak dapat lepas dari kehidupan manusia apalagi masyarakat pedesaan. Salah satu jenis tumbuhan yang paling banyak digunakan oleh masyarakat adalah bambu. Bambu adalah tumbuhan yang termasuk suku rumput-rumputan yang berwujud besar seperti pohon, tumbuh dengan menggunakan rimpang akar yang beruas-ruas dengan satu tunas di setiap ruasnya, berselang seling pada ruas berikutnya. Bambu di Indonesia mempunyai potensi yang sangat menjanjikan untuk dimanfaatkan dengan baik. Bambu merupakan tumbuhan yang mudah dikembangkan dan mempunyai daur hidup yang relatif cepat, dengan waktu panen hanya $3-4$ tahun. Pemanfaatan bambu telah banyak digunakan oleh masyarakat Indonesia.

Desa Tanjung merupakan salah satu desa dari 23 desa yang ada di Kecamatan Teriak Kabupaten Bengkayang, dengan luasan $\pm 1.276,02$ ha. Letak Desa Tanjung, Kecamatan Teriak, Kabupaten Bengkayang berada di kawasan hutan 
adat.Hutan adat adalah hutan di sekitar pemukiman, yang sejak dahulu turun temurun dikatakan kawasan tersebut adalah kawasan hutan adat, yang merupakan hutan yang berada dalam wilayah masyarakat hukum adat. Walaupun status kawasan hutan tersebut masih belum legal, namun proses legalisasi sedang dalam pembuatan. Masyarakat dayak Bekati yang mendiami Desa Tanjung, Kecamatan Teriak, Kabupaten Bengkayang merupakan penduduk asli, telah banyak mengenal bambu sejak turun temurun. Bambu dikenal karena telah memberikan berbagai manfaat dalam kehidupan mereka, namun Masyarakat disana belum banyak yang mengetahui pemanfaatannya secara maksimal. Padahal yang kita ketahui pemanfaatan bambu sebagai sumber alam yang berdaur ulang cepat terbukti dapat kontribusi yang tidak sedikit. Masyarakat Desa Tanjung Kecamatan Teriak Kabupaten Bengkayang memanfaatkan bambu sebagai bahan kerajinan tangan dimana bambu tersebut ditebang, dipungut dan dimanfaatkan untuk sendiri atau dijual. Batang bambu yang utuh dimanfaatkan sebagai bahan anyaman dinding, pagar rumah atau pagar ternak, lantai rumah dan obor, sedangkan batang bambu dalam bentuk olahan dimanfaatkan sebagai produk anyaman misalnya seperti : tanggui, bakul, raga, nyiru, takin, dan sumpit. Sedangkan untuk bambu yang kecil dimanfaatkan sebagai permainan tradisional seperti lantak, suling dan lainnya. Selain batang bambu masyarakat Desa Tanjung juga memanfaatkan rebung untuk dikonsumsi dan daun bambu juga dimanfaatkan oleh Masyarakat sebagai pembungkus makanan.

Bambu sudah sejak lama dikenal masyarakat sebagai tanaman yang bernilai ekonomis, namun hingga kini pola pemanfaatan bambu yang ada di Desa Tanjung masih sangat minim, karena masyarakat sekitar masih belum optimal dalam pemanfaatannya. Karena ketidaksediaan data dan informasi mengenai jenis dan pemanfaatan bambu yang digunakan oleh masyarakat Desa Tanjung, maka pemanfaatan bambu belum dilakukan secara maksimal. Oleh sebab itu perlu dilakukan penelitian tentang Pemanfaatan Jenis Bambu di Kawasan Hutan Adat Desa Tanjung Kecamatan Teriak Kabupaten Bengkayang. Tujuan penelitian untuk mendapatkan data jenis-jenis bambu yang dimanfaatkan oleh masyarakat serta mengkaji pola pemanfaatan bambu oleh masyarakat Desa Tanjung, Kecamatan Teriak, Kabupaten Bengkayang.

\section{METODOLOGI}

Penelitian dilaksanakan di Desa Tanjung Kecamatan Teriak Kabupaten Bengkayang \pm 4 minggu efektif dilapangan. Alat yang digunakan antara lain peta lokasi, GPS, peralatan untuk herbarium (alkohol, plastic packing, koran, gunting, isolasi dan label gantung), kamera, kuisioner, tally sheet, alat perekam, sarung tangan, parang, pisau dan gunting stek.

\section{Prosedur Penelitian}

\section{Jenis Data}

Data yang dikumpulkan dalam penelitian ini meliputi data primer dan data sekunder. Data primer yaitu berupa 
pengamatan secara langsung yang diperoleh dilapangan melalui wawancara langsung kepada masyarakat sebagai responden dengan bantuan kuisioner, melakukan identifikasi jenis bambu dengan menanyakan secara langsung kepada pengenal bambu, kemudian mencocokkan jenis yang dijumpai dengan pustaka. Data sekunde rmerupakan suatu data yang bersifat penunjang yaitu data yang diperoleh dari literature serta data yang lainnya. Data tersebut meliputi keadaan umum lokasi, letak dan luas, pendidikan, data jumlah penduduk serta keadaan social ekonomi masyarakat.

2. Teknik Pengumpulan Data

Metode yang digunakan dalam penelitian ini adalah metode survey dan observasi dengan teknik wawancara langsung. Pengumpulan data menggunakan alat bantu yaitu daftar pertanyaan atau kuisioner berupa bentukbentuk pertanyaan yang diarahkan kepada sejumlah responden. Pengambilan sampel dilokasi penelitian dilakukan dengan menggunakan purposive sampling. Pengumpulan data dilakukan dengan teknik wawancara langsung terhadap masyarakat sebagai responden dengan bantuan kuisioner. Berdasarkan metode dan teknik yang digunakan, maka responden sebagai obyek penelitian harus memiliki karakteristik atau persyaratan antara lain masyarakat asli Desa Tanjung Kecamatan Teriak Kabupaten Bengkayang, kepala keluarga atau anggota keluarga yang menggunakan bambu, sehat jasmani dan rohani, masyarakat yang tergolong masih terlibat dan berkecimpung pada pemanfaatan bambu, masyarakat yang mempunyai waktu memadai untuk diminta informasi serta usia minimal 15 tahun keatas.

3. Identifikasi Bambu

Identifikasi bambu merupakan kegiatan mengamati atau melihat secara seksama mengenai bentuk, ukuran, kedudukan, atau ciri-ciri dari jenis bambu baik pada rebung, cabang, batang, daun bambu tersebut. Proses identifikasi bambu dilakukan langsung di lapangan dan berpedoman pada kunci determinasi bambu yang berasal dari berbagai pustaka.

4. Pembuatan Herbarium

Herbarium

adalahsuatukoleksispesimentumbuhan yang diawetkan.Adapun tahapan dalam pembuatan herbarium antara lain:

a. Pengambilan contoh herbarium terdiri dari ranting lengkap dengan daunnya, dan lebih baik jika ada bunga serta buahnya.

b. Contoh herbarium dipotong dengan panjang sekitar $40 \mathrm{~cm}$.

c. Contoh herbarium diberi label gantung yang berukuran $3 \times 5 \mathrm{~cm}$. Label gantung berisi tentang nomor koleksi, inisial nama kolektor, tanggal pengambilan spesimen, nama local spesimen, dan lokasi pengambilan spesimen.

d. Contoh herbarium yang telah diberi label kemudian dirapikan dan dimasukkan kedalam lipatan kertas koran yang dilipat dua. Satu lipatan kertas koran untuk satu spesimen.

e. Lipatan kertas koran berisi spesimen ditumpuk menjadi satu dan dimasukkan kedalam kantong plastik bening berukuran 40x60 cm. 
f. Tumpukan spesimen disiram dengan alkohol $70 \%$ hingga seluruh bagian tumpukan tersiram merata, kemudian kantong plastik ditutup rapat agar alcohol tidak menguap keluar kantong.

g. Setelah sampai di tempat koleksi herbarium, tumpukan contoh herbarium dipress dalam sasak, kemudian dimasukkan kedalam oven dengan suhu $55^{\circ} \mathrm{C}$ selama 5 hari.

h. Setelah kering, herbarium kemudian diidentifikasi.

\section{Analisis Data}

Data yang diperoleh merupakan data kualitatif dan dianalisis secara deskriptif pada proses pemanfaatan bambu jenis apa dan bagian-bagian apa saja yang dapat digunakan oleh masyarakat sekitar.

\section{HASIL DAN PEMBAHASAN}

Berdasarkan hasil wawancara masyarakat dan identifikasi di lapangan yang dilaksanakan di Desa Tanjung Kecamatan Teriak Kabupaten Bengkayang peneliti menemukan 10 jenis bambu dari 4 genus yang berbeda, untuk lebih jelasnya dapat dilihat pada Tabel 1 .

Tabel 1. Nama jenis bambu dan yang dimanfaatkan oleh masyarakat Desa Tanjung. (Names of bamboo species and those used by the people of Tanjung Village).

\begin{tabular}{llll}
\hline No & Jenis Bambu & Nama Latin & Nama Daerah \\
\hline 1 & Bambu cina & Bambusa multiplex & Aur \\
2 & Bambu Ampel & Bambusa vulgaris & Au \\
3 & Bambu Betung & Dendrocalamus asper & Batunk \\
4 & - & Dendrocalamus hirtellus & Bincank/ Abi \\
5 & Bambu ater & Gigantochloa ater & Gare \\
6 & - & Gigantochloa balui & Madu \\
7 & Bambu lengka tali & Gigantochloa hasskarliana & Tarenk \\
8 & - & Gigantochloa levis & Surik \\
9 & Bambu Gading, b. kuning, b. & Schizostachyum brachycladum & Buru mari/ buru \\
& bali, b. panda bali /b. lemang & & \\
10 & - & Schizostachyum flexuosum & Pasa \\
\hline
\end{tabular}

Pemanfaatan bambu lebih banyak digunakan untuk anyaman, ritual, konsumsi serta bertani. Bagian bambu yang dimanfaatkan oleh masyarakat dayak bekati di Desa Tanjung antara lain batang bambu, rebung dan daun adapun bagian akar jarang dimanfaatkan. Bagian-bagian bambu yang dimanfaatkan oleh masyarakat dapat dilihat pada Tabel 2.

Tabel 2. Bagian bambu yang dimanfaatkan oleh masyarakat (The part of bamboo used by the community)

\begin{tabular}{lll}
\hline No & Nama Lokal & Bagian bambu yang dimanfaatkan \\
\hline 1 & Aur & Batang \\
2 & Au & Batang \\
3 & Batunk & Batang, Rebung \\
4 & Bincank/Abi & Batang \\
\hline
\end{tabular}




\begin{tabular}{lll}
\hline 5 & Gare & Batang, Rebung \\
6 & Madu & Batang \\
7 & Tarenk & Rebung, Batang \\
8 & surik & Batang, Rebung \\
9 & Buru mari/ buru & Batang, Daun \\
10 & Pasa & Batang, Daun \\
\hline
\end{tabular}

\section{Bentuk Pemanfaatan Bambu oleh Mayarakat Desa Tanjung}

Pemanfaatan tumbuhan khususnya bambu yang dilakukan di desa Tanjung saat ini merupakan pengetahuan turun temurun dari nenek moyang yang berasal dari hasil interaksi mereka dengan alam sekitarnya. Salah satu cara masyarakat agar bambu tetap terjaga kelestariannya adalah dengan cara yang sangat sederhana yaitu, waktu pengambilan bambu yang dilakukan oleh masyarakat dilakukan hampir sepannjang musim, bergantung pada kebutuhan masyarakat. Menurut masyarakat sekitar pengambilan bambu yang baik adalah pada hari musim hujan maupun kemarau, dikarenakan pemotongan yang dilakukan pada musim hujan mengakibatkan tunas muda banyak yang tumbuh dikarenakan kelembaban yang terjadi pada saat musim hujan. Berdasarkan hasil wawancara bersama masyarakat Desa Tanjung, proses dan hasil dari pemanfaatan bambu untuk berbagai keperluan seperti kerajinan, obatobatan, konsumsi, dan ritual antara lain sebagai berikut:

\section{Bambu untuk Kerajinan}

Proses pemanfaatan bambu untuk kerajinan meliputi penebangan dengan menggunakan alat sederhana seperti parang, sarung tangan dan alas kaki, bambu kemudian ditebang pangkalnya dipilih kemudian ditarik kebawah agar terlepas dari penyanggah, kemudin bambu dipotong sesuai kebutuhan, kemudiaan dibersihkan. Sesudah dibersihkan bambu disayat dipisahkan antara kulit luar dan kulit dalam, biasanya bambu bisa langsung dibentuk atau dianyam sesuai keperluan, dan ada juga di jemur beberapa hari untuk melenturkan kulit bambu, dan bahkan ada yang direndam untuk memperkuat sesuai dengan kepeluan dan kebutuhan masyarakat. Bagian bambu untuk kerajinan ini hanya bagian batang sedang dan agak tua.

Bambu yang dimanfaatkan untuk kerajinan ada 13 macam antara lain: sicup (Gambar 1a). dibuat dari jenis bambu bincank dan pasa, alat ini digunakan untuk menangkap ikan di sungai. Tangkin atau basek (Gambar 1b) dibuat dari bincank, abi dan pasa yang digunakan untuk membawa sayur sayuran dari kebun atau hutan. Ijo (Gambar 1c ) terbuat dari jenis bambu tarenk dan bincank, alat ini untuk menangkap ikan yang ukurannya besar pada saat nangguk atau nuba sawah. Ragak (Gambar 1d) terbuat dari bambu bincank dan abi, alat ini biasa hanya untu menyimpan sayur yang sudah di 
bersihkan dan untuk menyimpan bawang, terong dan lain. Kerungan (Gambar 1e) dibuat dari jenis bambu tarenk dan bincank, alat ini dimanfaatkan masyarakat untuk kandang ayam untuk bertelur. Basek ransang (Gambar 1f) terbuat dari bambu abi dan pasa, alat ini dimanfaatkan

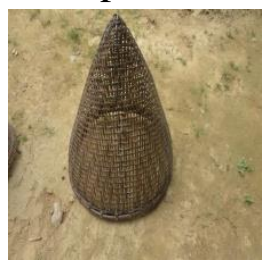

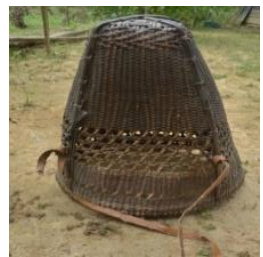

b

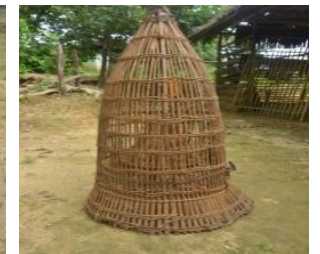

c

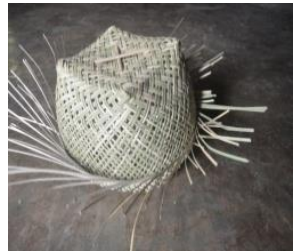

d

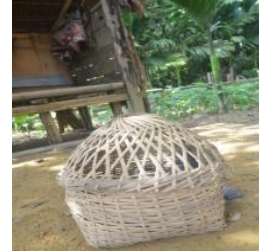

e

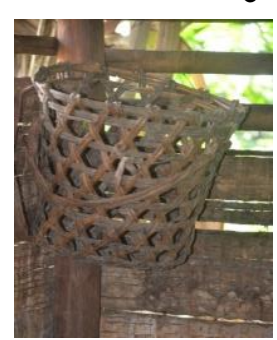

$\mathrm{f}$

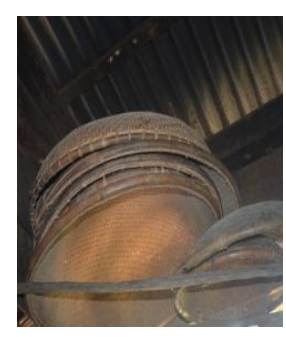

$\mathrm{g}$

Gambar 1. Bambu untuk Anyaman a.sicup; b.takin; c.ijo; d. ragak; e. kerungan; f.basek ransang dan g.lipak(Results of webbing a.Sicup; b.Takin; c.Ijo; d.Ragak; e.Kerungan; f.Basek ransang; g. Lipak).

Bambu yang dimanfaatkan untuk anyaman di Desa Tanjung ini lebih banyak dibandingkan dengan penelitian Sumiarti (2016) di Dusun Padan desa Tiang Tanjung Kecamatan Mempawah Hulu yang mendapatkan 4 pemanfaatan yaitu ragak, bubu, nyiru, tengkaleng.

\section{Bambu untuk Obat}

Proses pemanfaatan bambu untuk obat berbeda dengan pemanfaatan lainnya, pemanfaatan bambu untuk obat hanya pengambilan pucuk daun bambu dan hanya untuk jenis bambu madu (Gigantochloa balui). Bambu yang dimanfaatkan oleh masyarakat ada 2 yaitu hanya untuk mengobati panas dalam dan gatal-gatal. Hanya pucuk daun bambu yang digunakan dengan cara ditumbuk dan kemudian di bungkus dengan daun dan kemudian dibakar, setelah itu disedu dengan air panas atau hangat.

\section{Bambu untuk Konsumsi}

Proses pemanfaatan bambu untuk konsumsi hampir sama dengan pengambilan untuk kerajinan hanya saja bambu untuk konsumsi berbeda jenis dengan bambu untuk kerajinan. Masyarakat memanfaatkan rebungnya untuk konsumsi, selain itu digunakan juga sebagian batangnya yang masih muda yang dipotong sesuai dengan 
selera masing-masing. Daunnya yang masih bagus dilipat dan diikat kemudian direndam beberapa jam. Setelah itu ditiriskan dan dijemur, barulah daun bisa digunakan untuk membungkus makanan.

Bambu yang dimanfaatakan untuk konsumsi ada 3 macam pemanfaatan antara lain jenis rebung tarenk (Gigantochlo hasskarliana), rebung betung (Dendrocalamus asper), rebung surik (Gigantochloa levis), rebung gare (Gigantochloa ater). (Gambar 2a) selain untuk dikonsumsi, masyarakat memanfaatkan batangnya untuk keperluan tani. Jenis bambu buru
(Schizostachyum brachycladum) lemang (Gambar 2b dan 2c) selain daun bambu untuk membungkus makanan yang isinya terbuat dari beras ketan, kacang tanah dan dicampur dengan kapur sirih, masyarakat juga memanfaatkan batang bambu untuk memasak lemang dan bara, untuk lemang terbuat dari beras ketan dicampur dengan air santan, sedangkan bara bisa dengan beras ketan bisa juga dengan beras biasa tidak dicampur dengan santan karena bara dimanfaatkan untuk ritual seperti balengang atau pada saat pembukaan lahan untuk berladang. Untuk lebih jelas dapat dilihat pada Gambar 2:

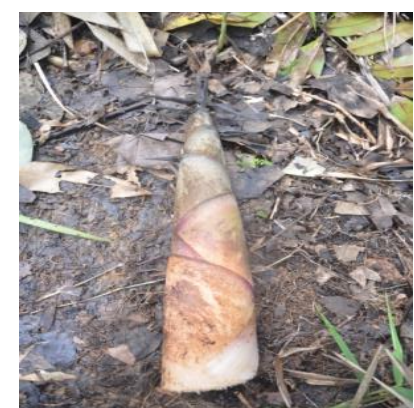

a

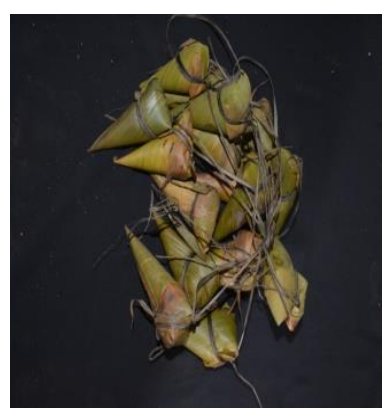

b

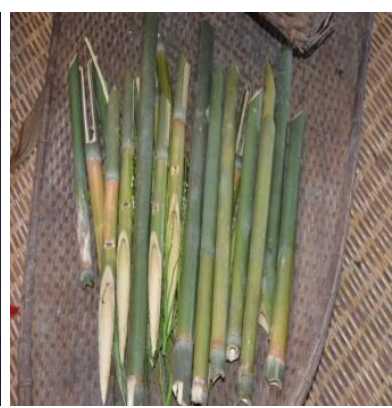

c

Gambar 2. Bambu untuk Konsumsi a.rebung; b.kue daun buru; c.lemang(Bamboo for consumption a. Bamboo shoots; b. Rushed leaf cake; c. Lemang)

Pemanfaatan bambu untuk konsumsi di Desa Tanjung lebih banyak dibandingkan dengan penelitian Usman (2019), di Desa Babane Kecamatan Samalantan Kabupaten Bengkayang, yang hanya mendapatkan satu jenis bambu untuk konsumsi.

\section{Bambu untuk Ritual Adat}

Proses pemanfaatan bambu untuk ritual hampir sama cara pengambilannya dengan untuk kerajinan dan konsumsi. Bambu yang akan digunakan untuk ritual di potong dan di pangkas sebagian dan masih tertinggal ranting dan daun, namun ada juga yang pengambilannya hanya bagian batang saja.Pengambilan bambu untuk ritual hanya diperbolehkan dua hari sebelum ritual dilakukan. Hal ini disebabkan adanya aturan adat. Ritual ini biasa hanya dilakukan di rumah dan di luar rumah.

Bambu yang dimanfaatkan untuk ritual adat ada 7 macam antara lain jenis bambu buru dan buru mari (Schizostachyum brachycladum) 
(Gambar 3a dan 3d), dimanfaatkan masyarakat sebagai sune bara dan lemang telur, sune bara yang artinya untuk upacara pemanggilan roh dan biasa dimanfaatkan untuk menyembuhkan orang sakit (balenggang) serta lemang telur dimanfaatkan masyarakat untuk upacara ibu hamil atau pemandian bayi yang berusia 7 bulan, yang artinya agar antara ibu hamil dan bayi tidak kepilu atau tidak mudah takut. Sedangkan untuk jenis bambu bincank (Gambar 3b), dijadikan sebagai Osok bu'ut atau ranting bambu yang artinya dimanfaatkan masyarakat untuk upacara bayi yang berusia 3-7 bulan agar tidak mudah melihat roh halus. Jenis bambu au (Gambar 3c) dihasilkan sebagai cangkang tempayan, yang dimanfaatkan masyarakat untuk upacara gawai dan pesta perkawinan yang artinya untuk memberi sesajian kepada roh leluhur yang sudah meninggal. Jenis bambu abi (Gambar 3e) dihasilkan sebagai cankang telur, yang dimanfaatkan sebagi menghantar roh pulang ketempat asal yang artinya agar roh tidak mudah kembali kepedesaan. Jenis bambu buru mari (Gambar 3f) dijadikan sebagai cangkang mangkok yang dimanfaatkan sebagai upacara pembukaan lahan baru atau berladang, yang artinya agar apapun yang ditanam akan memberikan hasil yang sesuai diharapkan. Untuk lebih jelas dapat dilihat pada Gambar 3:

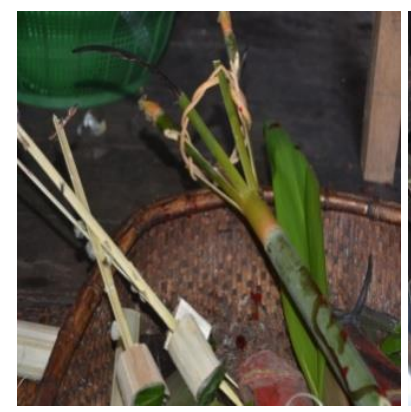

a

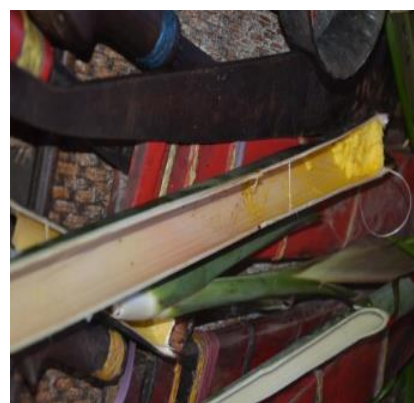

d

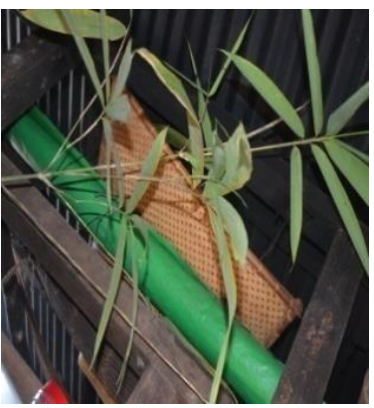

b

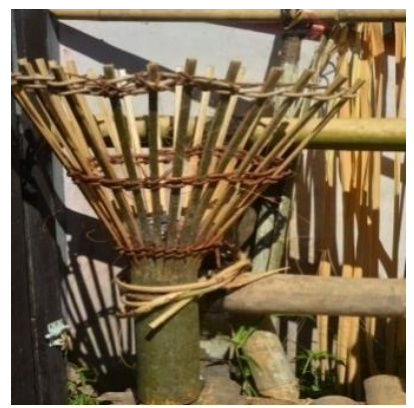

c

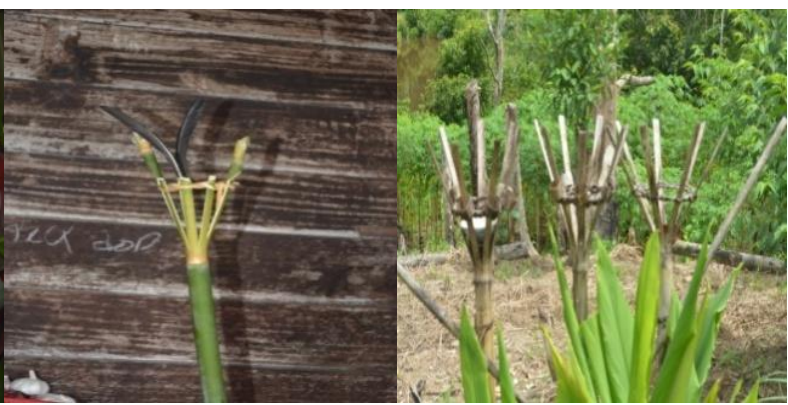

e

f

Gambar 3.Bambu untuk Ritual Adat a.sune bara; b.osok bu'ut/ ranting; c.cangkang tempayan;d.lemang telur; e.cangkang telur; f.cangkang mangkok mangkok (Customary rituals a.Empress bara; b.Osok bu'ut/twigs; c.Jug Shells; d.Lemang eggs; e.Eggshell; f.Bowl) 
Pemanfaatan Bambu untuk Ritual di Desa Tanjung lebih banyak dibandingkan dengan pemanfaatan bambu untuk ritual di Desa Semade Kecamatan Banyuke Hulu Kabupaten Landak yang hanya mendapatkan 1 jenis bambu dan digunakan untuk kegiatan Ritual yaitu bagian daunnya (Yeriko, 2018).

\section{Bambu untuk Alat Bertani}

Proses pemanfaatan bambu untuk alat bertani meliputi penebangan dengan alat sederhana seperti parang, sarung tangan, dan alas kaki, bambu kemudian ditebang pangkalnya, dipilih kemudian di tarik kebawah agar terlepas dari penyanggah, kemudian bambu dipotong sesuai keperluan, kemudian dibersihkan dan dibentuk sesuai dengan keperluan. Bambu untuk alat bertani ada 15 macam pemanfaatan, yang paling banyak dimanfaatkan untuk alat bertani dan kebutuhan lainnya yaitu: pension (Gambar 4a) dimanfaatkan untuk meniup api di dangau dari jenis bambu surik (Gigantochloa levis), taha'n binti (Gambar 4b) dimanfaatkan untuk mengikat tanaman dan bisa untuk pancing dari jenis bincank (Dendrocalamus hirtellus), Taha'n Aro (Gambar 4c) dimanfaatkan untuk mengikat daun atap dari jenis bambu surik (Gigantochloa levis), jembatan (Gambar 4d) dimanfaatkan untuk jembatan penyeberangan sawah atau sungai, dari jenis bambu (Gigantochloa ater), tanggul sawah (Gambar 4e) dimanfaatkan untuk menahan air sawah agar tidak mengalir, dari jenis bambu (Gigantochloa ater). Untuk jelasnya dapat dilihat pada Gambar 4 berikut ini

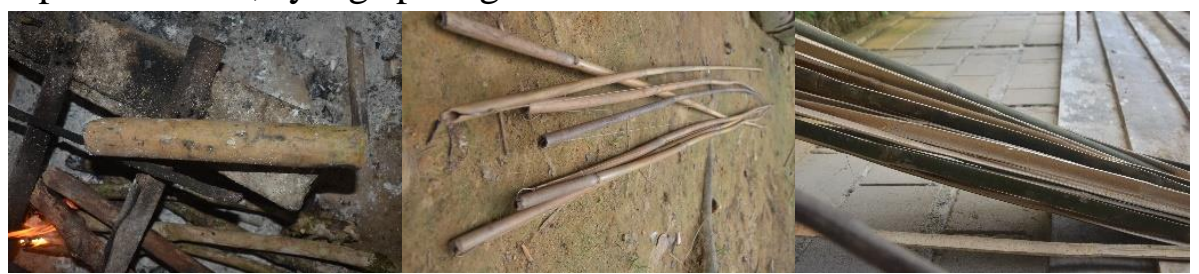

a

b

c

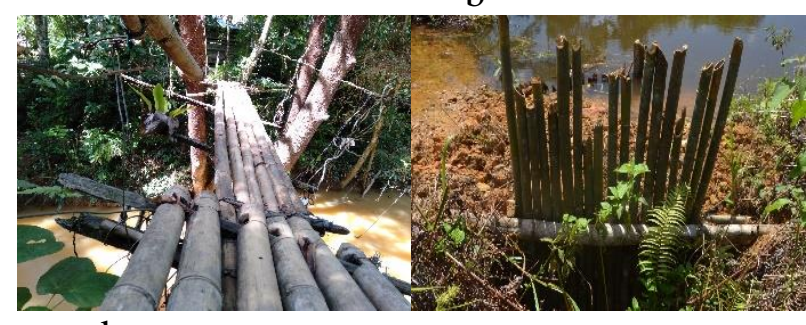

d

$\mathrm{e}$

Gambar . 4 Bambu untuk Bertani a. Pension; b. Taha'n Binti; c. Taha'n Aro; d. Jembatan sungai; e. Tanggul sawah (Bamboo for farming a. Pension; $b$. Taha'n Binti; c. Taha'n Aro; d.river bridge; e. rice field embankment)

\section{Kesimpulan}

1. Berdasarkan data yang diperoleh di lokasi penelitian tercatat 10 jenis bambu yang dimanfaatkan oleh masyarakat

Desa

Tanjung Kecamatan Teriak Kabupaten Bengkayang, yang ditemukan adalah jenis Aur (Bambusa multiplex), Au 
(Bambusa vulgaris), Batunk (Dendracalamus asper), Bincank/ Abi (Dendrocalamus hirtellus), Gare (Gigantochloa ater), Madu (Gigantochloa balui), Tarenk (Gigantochloa hasskarliana), Surik (Gigantochloa levis), Buru maril Buru (Schzostachyum brachycladum), Pasa (Schzostachyum flexuosum), .

2. Pemanfaatan semua jenis bambu oleh masyarakat di Desa Tanjung dalam bentuk kerajian (13 macam pemanfaatan), Konsumsi (3 macam pemanfaatan), ritual adat (7 macam pemanfaatan), obat (2 macam pemanfaatan) dan alat bertani (15 macam pemanfaatan).

\section{Saran}

Perlu adanya kesadaran dari masyarakat untuk membudidayakan bambu secara berkelanjut, dan perlu adanya penyuluhan tentang teknik mengayam yang lebih baik dan variatif agar meningkatkan nilai ekonomi masyarakat serta perlu adanya peran serta inisiatif dari pemerintah daerah dan dinas untuk tetap melestarikan tumbuhan bambu guna mempertahankan kekayaan alam.

\section{DAFTAR PUSTAKA}

Anonim. 2019.2 Desa Longpait.http://id.wikipedia.org/w iki/com. 20 Maret 2019.

Ali Murtodo dan Dwi Setyati. 2015. Inventarisasi Bambu di Kelurahan Antirogo Kecamatan Sumbersari Kabupaten Jember. Jurusan Biologi Fakultas Matematika dan Ilmu Pengetahuan Alam, Universitas Jember.
Arsad, E, 2014. Global Forest Resources Assessment. Update 2005. Indonesia Cauntry Report on Bamboo Resources. Forest Resources Assessment Working Paper (Bamboo) Food and Agreculture Organization of The United Nations, Forestry Departement and International Network for Bamboo and Rattan. Jakarta.

Arsad, E 2014, Bambu Tanaman Multi Manfaat Pelindung Tepian Sungai. Info Hasil Hutan Vol 2. No. 1. Pusat Penelitian dan Pengembangan Teknologi Hasil Hutan.

Sumiarti, Iswan D, dan Sarma. 2016. Tradisi Masyarakat, Dusun Padan Terhadap Pemanfaatan Jenis-Jenis Bambu pada Kawasan Hutan di Desa Tiang Tanjung Kecamatan Mempawah Hulu Kabupaten Landak. Jurnal Hutan Lestari. 4 (3): 361-370.

Usman. 2019 Pemanfaatan Bambu oleh Masyarakat Desa Babane Kecamatan Samalantan Kabupaten Bengkayang. Jurnal Hutan Lestari. Vol. 7 (2) : 655667

Widjaja, E. A. 2019. The Spectacular Indonesian Bamboos. Polagrade, Jakarta. 188 hal.

Yeriko. 2018 Studi Jenis dan Pemanfaatan Bambu oleh Masyarakat Dusun Perigi Desa Semade Kecamatan Banyuke Hulu Kabupaten Landak. Jurnal Hutan Lestari. Vol. 6 (1) : 131136 